\title{
Resenha
}

\section{Cine[mão] e a crítica fisting de Helder Thiago Maia}

ISSN: 2358-0844

n. II, v. I mai. -out. 2019 p. $454-458$.

Livro resenhado: MAIA, Helder Thiago. Cine[mão]: espaços e subjetividades darkroom. Salvador: Editora Devires, 2018.

\section{Jorge Vicente Valentim ${ }^{1}$}

Na década de 1980 - e já lá se vão mais de 30 anos -, a ensaísta norte-americana Eve Kosofsky Sedgwick propunha, no seu conhecido trabalho sobre a literatura inglesa e as representações da homossexualidade masculina (Between Men, 1985), a terminologia "desejo homossocial masculino", com a derivação "homossociabilidade", para refletir sobre os padrões emergentes de amizades, mentorias, exigências e rivalidades masculinas, e suas alterações e reverberações de acordo com as classes sociais dos agentes envolvidos nas respectivas relações.

O texto tornou-se um ponto referencial para os estudos queer, não só porque possibilitava um caminho prolífero de análises sobre a homossexualidade e seus ecos em diferentes sistemas literários, mas porque também fomentava discussões pontuais sobre as questões de gênero, envolvendo, a partir daí, uma outra categoria narrativa: o espaço. Afinal, essas relações não se davam ao acaso, mas, quase todas surgiam e se desenvolviam dentro de um ambiente de incidência maior ou menor.

A idéia de iniciar minhas breves considerações sobre a mais recente publicação do jovem pesquisador Helder Thiago Maia, Cine[mão]: espaços e subjetividades darkroom, sob a chancela

${ }^{1}$ Professor Associado do Departamento de Letras e Professor Permanente do Programa de Pós-Graduação em Estudos de Literatura (PPGLit) da UFSCar. Professor Colaborador do Programa de Pós-Graduação em Estudos Literários da UNESP-FCLAr. E-mail: jvvalentim@gmail.com 
da Editora Devires, com Eve K. Sedgwick é proposital. Para o leitor da obra, poderá causar até uma certa surpresa, já que ela não se encontra no elenco escolhido por ele para os pressupostos teóricos. Mas, não se iluda o leitor, porque a ausência não é gratuita. A proposta de Helder é exatamente colocar não apenas o dedo na ferida, mas abri-la e expô-la com a mão, num exercício muito sucedido, que bem pode ser comparado com a prática erótica de uma crítica fisting.

Explico-me. O trabalho de Helder constitui uma análise detida e cuidadosa, como o seu título já revela, sobre um espaço específico de ocorrência e livre fluidez da homossexualidade masculina: os cinemas com suas salas escuras (os darkrooms), que propiciavam encontros eróticos fortuitos e sem compromissos. Trata-se, portanto, de uma topoanálise direcionada e explícita, visando interrogar como algumas representações literárias investem e se debruçam sobre o tema e sobre os seus locais de ocorrência.

Ora, se, por um lado, Sedgwick não comparece - e não poderia comparecer, porque Helder não está interessado nos desejos homossociáveis, mas nas relações explícitas de prazer e de liberdade entre atores e atrizes "dissidentes sexuais" (MAIA, 2018, p. 72) -, por outro, toda uma gama de teóricos sobre a categoria narrativa do espaço lá está, desde os mais conhecidos de língua francesa, quanto os da fortuna crítica em espanhol, em inglês e em português, a saber: Gaston Bachelard, Marc Augé, Michel Blanchot, Roland Barthes, Antonio Candido, Antonio Dimas, Oziris Borges Filho, Francisco Assis da Costa José Miguel Cortés, Juan Pablo Sutherland, Paul Beatriz Preciado e Jesús Camarero, dentre outros.

Interessante observar que, mesmo se valendo de todo um repertório já consagrado pela crítica literária, Helder Maia não abre mão do caminho metodológico escolhido, afinal, não se trata, apesar do peso canônico de muitos desses ensaístas, de um trabalho de viés tradicional e ortodoxo, muito pelo contrário. Neste sentido, a presença de nomes indicadores de um caminho diverso e que preza pela liberdade da escolha do tema e dos seus objetos já demonstra a sua opção por uma epistemologia de resistência. Não à toa, por exemplo, Gilles Deleuze, Teresa de Laurentis, Michel Foucault e Virgínia Woolf são os escolhidos para as suas epígrafes. Além destes, somam-se outros, mais alinhados a uma práxis crítica dialogante com os estudos culturais e com as questões sobre as dissidências sexuais, tais como Denilson Lopes, James Green, Leandro Colling e Mario Cesar Lugarinho, apenas para ficar nos mais importantes.

Neste exercício muito bem sucedido de articulação teórico-crítica, Helder consegue apresentar o seu corpus e o seu objetivo, de forma direta e pontual, sem rodeios: "O cinema pornô foi escolhido 
não só por um desejo pessoal de trabalhar com alguns textos que dificilmente fazem parte da crítica, da historiografia e do ensino literário, mas principalmente por uma vontade que tem atravessado constantemente minha trajetória como pesquisador, de pensar a literatura a partir de espaços físicos que tradicionalmente têm sido construídos como abjetos. Em trabalhos anteriores analisei, por exemplo, espaços como banheiro público, darkroom e cruising bar" (MAIA, 2018, p. 17).

Ou seja, o corpulento trabalho apresentado, ao longo das 321 páginas, constitui o resultado de uma pesquisa profunda, bem cuidada e amadurecida sobre o tema (aqui, é preciso lembrar que a presente publicação é a versão em livro de sua tese de doutorado pela UFF, com orientação da Profa. Dra. Livia Maria de Freitas Reis Teixeira e co-orientação do Prof. Dr. Mário César Lugarinho, da USP, que assina um belíssimo e pertinente prefácio), com uma articulação teórico-crítica coerente e com um agenciamento de autores e obras que propiciam resultados bem conseguidos. Basta observar, neste sentido, que Helder não se detém apenas na especulação dos espaços dos cinemas pornô ou fica circunscrito a uma descrição arquitetural dos quadrantes urbanos onde as práticas homossexuais, consideradas abjetas pelos discursos oficiais, ocorrem. De forma perspicaz, Helder Maia sublinha que nenhum espaço existe sem a presença do(s) homem(ns), mas estes também não podem ser suficientes para condicionar o homem. Por isso, a divisão da obra se apresenta de forma coerente, posto que, para além dos esclarecimentos dos pressupostos teóricos, os "Espaços Darkroom: o cine[mão]" e os seus agentes, aqueles que dão humanidade aos locais onde as relações eróticas efetivamente acontecem: "Subjetividades Darkroom: os três milhões de perversos".

Assim, a ideia de uma crítica fisting, de um exercício crítico eroticamente pensado e prazeroso, de uma análise aberta e explícita, sem rodeios, se concretiza no trabalho de Helder Thiago Maia, na medida em ele não abre mão de pensar os espaços conjugados aos seus atores. E não apenas os que se manifestam nas telas dos cinemas, mas, principalmente, aqueles que fazem do escuro e da fisicalidade das salas os seus palcos de performance e de prazer: "À parte desses espaços e projeções clandestinas, podemos afirmar que o cinema sempre foi um local de encontro dos dissidentes sexuais, ainda que nem sempre tenha sido um espaço de maior permissividade sexual” (MAIA, 2018, p. 72).

A mão crítica que penetra o tema jamais poderia executar o seu objeto de forma inconsequente. Por isso, Helder se debruça sobre um elenco considerável de autores e obras que tematizam os espaços e os seus atores. Assim, de Capadócio Maluno a Luis Capucho, de Jorge Jaime a Cabrera Infante, de Gasparino Damata a Pablo Pérez, de Nestor Perlongher a Pedro Lemebel, o leitor vai se deparando com um repertório expressivo de escritores que, em crônicas, contos, poemas e romances, deslindaram os 
meandros mais escuros dos espaços cinematográficos e criaram universos dissidentes, com personagens que, com seus corpos, "reagem ativamente aos filmes, mas através de prazeres produzidos nos próprios corpos; a sociabilidade ressurge, mas para o prazer orgiástico" (MAIA, 2018, p. 113).

Mas o que Helder Thiago Maia procura ler nestes espaços é também a liberdade do cinema darkroom poder ser lido como uma espécie de “corpo-sem-órgãos, um corpo povoado de multiplicidades, onde $\mathrm{o}$ funcionamento tradicional dos órgãos dos sentidos encontra-se desterritorializado e desierarquizado" (MAIA, 2018, p. 139). Ora, se os sentidos se misturam, numa prazerosa sinestesia, e as hierarquias se quebram, não apenas o espaço propicia as experiências dissidentes, mas possibilita o livre trânsito de indivíduos que se comprazem, enquanto agentes concretizadores da própria dissidência. Logo, a proposta de investigar as "Subjetividades darkroom" que circulam nos cinemas constitui um caminho coerente de leitura para textos de autores como os já citados Luis Capucho, Nestor Perlongher e Gasparino Damata, além de Ricardo Videla, Naty Menstrual, Antonio Carlos Viana e Pedro Lemebel, dentre outros.

Aqui, parece-me, o ensaio de Helder Maia ganha uma envergadura importante, na medida em que sai da dimensão exclusiva sobre os homossexuais e abre espaço para refletir sobre outras dissidências sexuais, mostrando, inclusive, o ganho que a literatura tem sobre outras áreas do saber, quando o assunto centra-se na representação das subjetividades darkroom, presentes nos espaços dos cinemas. De acordo com o autor, “[...] é no campo literário onde encontramos uma maior polifonia e posicionalidade dos corpos trans no cinema pornô. Dessa forma, podemos dizer que a literatura rompe com a narrativa da antropologia, que circunscreve esses corpos exclusivamente à prostituição, e reescreve a história travesti no cinema pornô também como usuárias, a partir das autoras trans e travestis" (MAIA, 2018, p. 249).

Concluo, portanto, sublinhando um aspecto importante no trabalho de Helder Thiago Maia. Trata-se, na verdade, de uma proposta duplamente originalíssima, não só porque se desvia dos lugarescomuns esperados pela crítica mais ortodoxa, rasurando, de vez, as tentativas de manutenção de um conservadorismo crítico - afinal, a abordagem é sobre uma categoria narrativa específica, no entanto é sobre espaços e subjetividades darkroom -, mas também porque, ao interpelar as subjetividades (exatamente no plural), ele tem consciência de que não poderia circunscrever seu exercício crítico a apenas um núcleo das dissidências sexuais. Assim sendo, o ensaio realiza-se de forma coerente e segura. Aliás, em tempos de exceção, onde temos de ouvir que meninos vestem azul e meninas vestem rosa, exercícios de epistemologias de resistência, como os de Helder Thiago Maia, tornam-se necessários, 
urgentes e muito bem vindos.

Ao final - e sem querer roubar prazer da leitura ao leitor -, percebe-se que, de mero local de encontro e de algum flerte a espaço de consecução orgiástica e de pegação, os cinemas e os seus atores e atrizes vão sendo estudad@s e descortinad@s pela mão segura e (por que não dizer?) corajosamente fistadora de Helder Thiago Maia. Será isto um bem pensado exercício crítico-erótico do ensaísta para seduzir e conquistar o leitor a uma experiência orgiástica tão ousada quanto aquelas, por ele estudadas? Tendo a acreditar que sim, mas como, felizmente, a leitura e a sua recepção são atividades individuais e subjetivas, fica, aqui, apenas, o convite, lembrando a sempre pertinente voz poética de Fernando Pessoa: "Sentir? Sinta quem lê!" (PESSOA, 2001, p. 165).

\section{Referências}

MAIA, Helder Thiago. Cine[mão]: espaços e subjetividades darkroom. Salvador: Editora Devires, 2018.

PESSOA, Fernando. Obra poética. Rio de Janeiro: Nova Aguilar, 2001. 